\title{
Pathological diagnosis and treatment outcome of gastric metastases from small cell lung cancer: A case report
}

\author{
YANMEI PENG ${ }^{1}$, QING LIU ${ }^{2}$, YE WANG $^{3}$, AIPING SONG $^{3}$, HUA DUAN $^{4}$, \\ YUQIN QIU ${ }^{4}$, QIANG $\mathrm{LI}^{4}$ and HUI-JUAN CUI ${ }^{2}$ \\ ${ }^{1}$ Department of Oncology, Fangshan Hospital, Beijing University of Chinese Medicine, Beijing 102400; \\ Departments of ${ }^{2}$ Integrative Oncology and ${ }^{3}$ Pathology, China-Japan Friendship Hospital, Beijing 100029; \\ ${ }^{4}$ Department of Graduate Schools, Beijing University of Chinese Medicine, Beijing 100029, P.R. China
}

Received June 11, 2018; Accepted April 25, 2019

DOI: $10.3892 / \mathrm{ol} .2019 .10484$

\begin{abstract}
Small cell lung cancer (SCLC) is a type of lung cancer characterized by a rapid disease progression and poor prognosis. Its diagnosis is often accompanied by distant metastasis. A literature review revealed that metastases to the stomach from breast, lung and esophageal cancer are frequently reported. While SCLC is a common pathological subtype of lung cancer, literature on SCLC with gastric metastases is sporadic. The present study reviewed the literature using databases, including PubMed, WanFang Data and China National Knowledge Infrastructure, to analyze the clinicopathological features and outcome of patients with gastric metastases from SCLC. A total of 11 case reports and 6 retrospective studies comprising of 19 cases were compared and analyzed. In addition to the aforementioned studies, a case study describing a patient who survived for 10 months following a diagnosis of SCLC with gastric metastases is presented. The aim of the present study was to increase the understanding regarding the diagnosis and treatment of SCLC gastric metastasis.
\end{abstract}

\section{Introduction}

The diagnosis of gastric metastasis is challenging in a clinical setting due to a lack of typical symptoms, with the majority of cases being identified following an autopsy (1). Previous studies investigating metastatic tumors in the stomach revealed that lung, breast and esophagus are common primary tumor sites, and renal cell carcinoma and malignant melanoma were also identified $(2,3)$. A retrospective analysis of 54 cases of metastatic tumors in the stomach reported that 16 cases $(25 \%)$ originated from different types of lung cancer, including

Correspondence to: Dr Hui-Juan Cui, Department of Integrative Oncology, China-Japan Friendship Hospital, 2 Yinghua Dongjie Street, Beijing 100029, P.R. China

E-mail: chjzryhyy@sina.com

Key words: small cell lung cancer, gastrointestinal metastases, immunohistochemical staining, chemotherapy, prognosis non-small cell lung cancer (NSCLC) and small cell lung cancer (SCLC) (4). In contrast to primary NSCLC, SCLC is a less common type of lung cancer that presents with gastric metastases (5-8). SCLC is characterized by a rapid progression and a poor prognosis in patients (9). Chemotherapy and supportive care are routine therapeutic choices for the treatment of late-stage SCLC (10). The current study presents the case of a female patient diagnosed with SCLC with gastric metastasis, who benefited from a 10 month survival time following chemotherapy. A review of the current literature was also provided to contextualize the findings of the present study.

\section{Case report}

A 77 year old female with no history of smoking or drinking was admitted to the China-Japan Friendship Hospital (Beijing, China) on May 23, 2016 after exhibiting a poor appetite, abdominal distension after meals and occasional epigastralgia for one month. A chest computed tomography (CT) scan revealed masses in the left hilar region and left lower lobe of the lung, indicating the presence of malignant tumors. In addition, a dispersed distribution of nodules was identified in left and right lung lobes with lymph node tumefaction in the left cervical, cardiophrenic angle and retroperitoneal regions. The left adrenal gland presented with thickening due to the presence of nodules, suggesting the possibility of metastases. In addition, pericardial effusion was observed (Fig. 1A). An abdominal and pelvic CT scan revealed that in the hepatic hilar and pancreatic peripheral regions, mesenteric roots and retro-peritoneum, lymph node tumefaction and partial integration were present, indicating extensive metastasis (Fig. 2A). A head CT and radionuclide bone imaging identified no abnormalities. Venous blood of the patient was collected to detect tumor markers by electrochemiluminescence following centrifugation. The normal range of the tumor markers carbohydrate antigen 125 (CA125) and neuron specific enolase (NSE) are $<35.00 \mathrm{U} / \mathrm{ml}$ and $<16.3 \mathrm{ng} / \mathrm{ml}$, respectively (11); the levels of CA125 and NSE in the patient's blood were above the normal range (Fig. 3). A circulating tumor cell count of 14.15 FU/3 ml was detected in the serum sample collected at the first visit, a level which was considerably elevated 

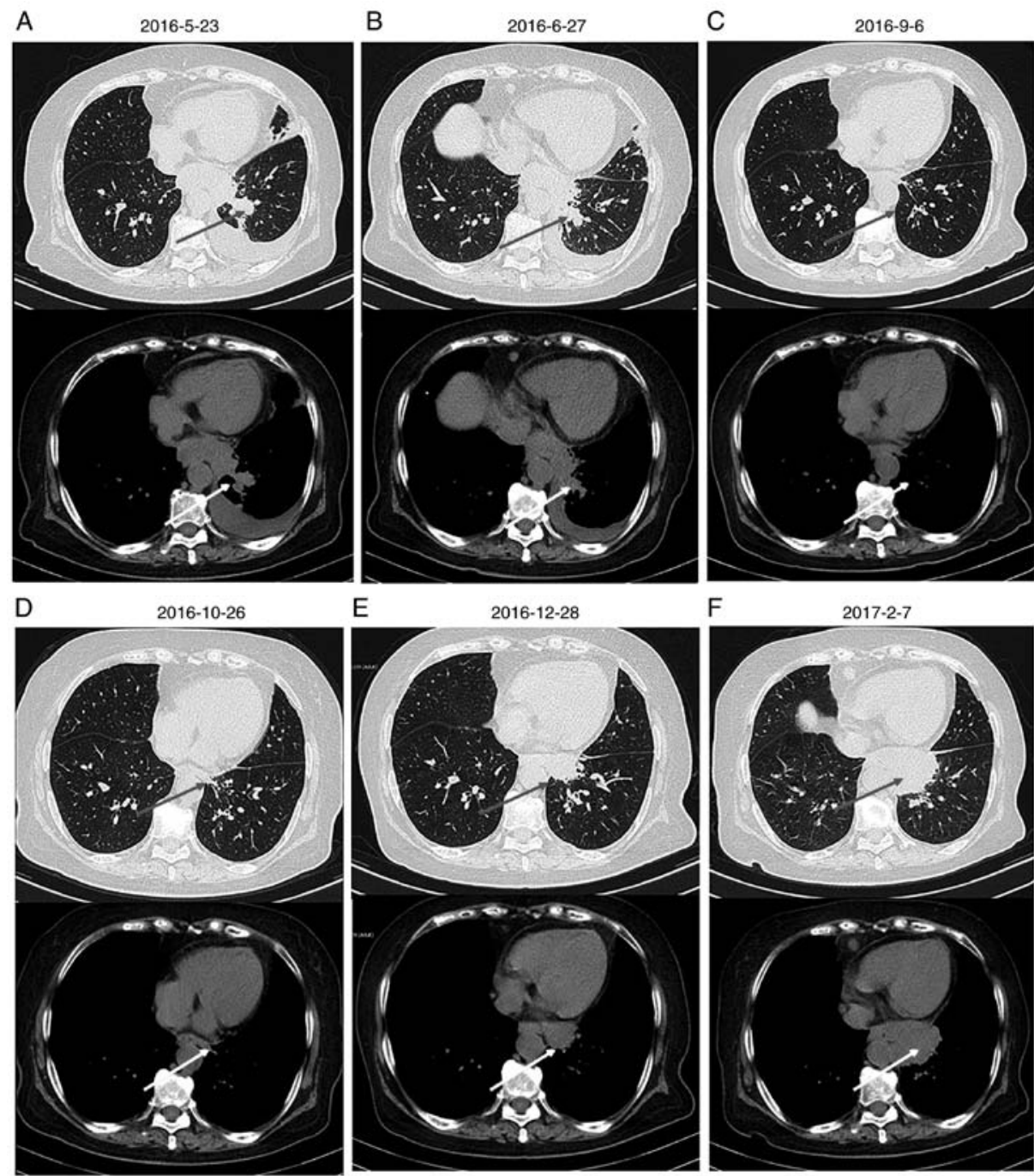

Figure 1. Chest computed tomography scan of the patient. Images were collected on (A) 2016-5-23, (B) 2016-6-27, (C) 2016-9-6, (D) 2016-10-16, (E) 2016-12-28 and (F) 2017-2-7. The arrows indicate the location of the tumor.

A

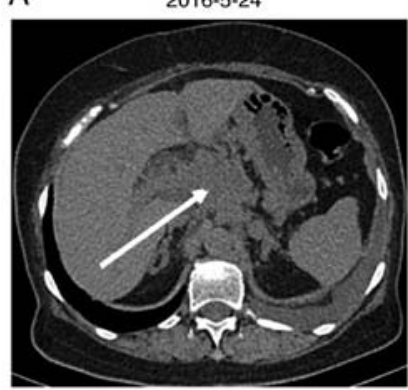

D

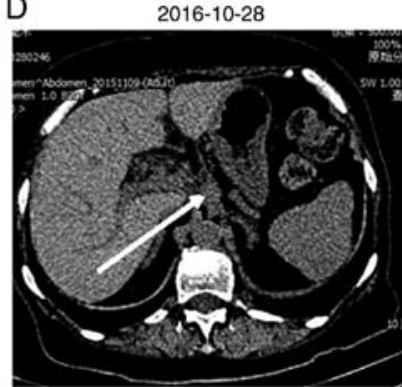

B

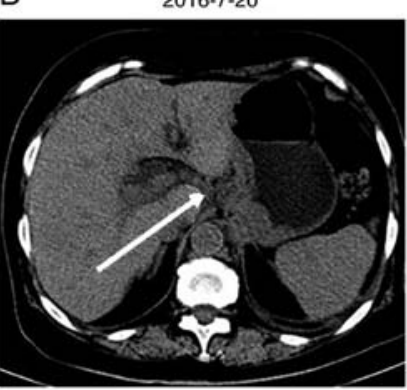

E

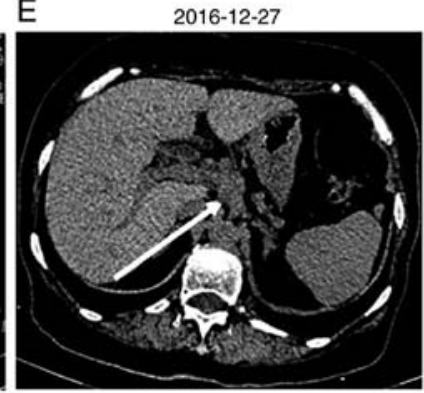

C

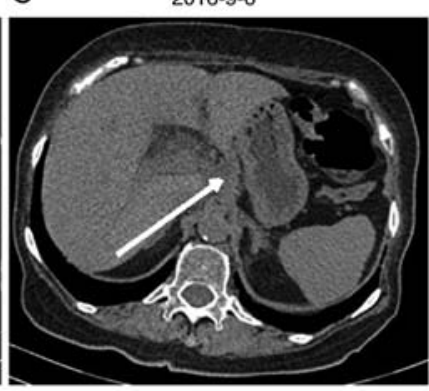

$\mathrm{F}$

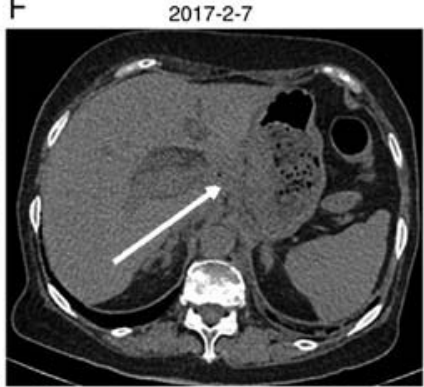

Figure 2. Abdominal computed tomography scans of the patient. Images were collected on (A) 2016-5-24, (B) 2016-7-20, (C) 2016-9-6, (D) 2016-10-28, (E) 2016-12-27 and (F) 2017-2-7. The arrows indicate the location of the tumor. 


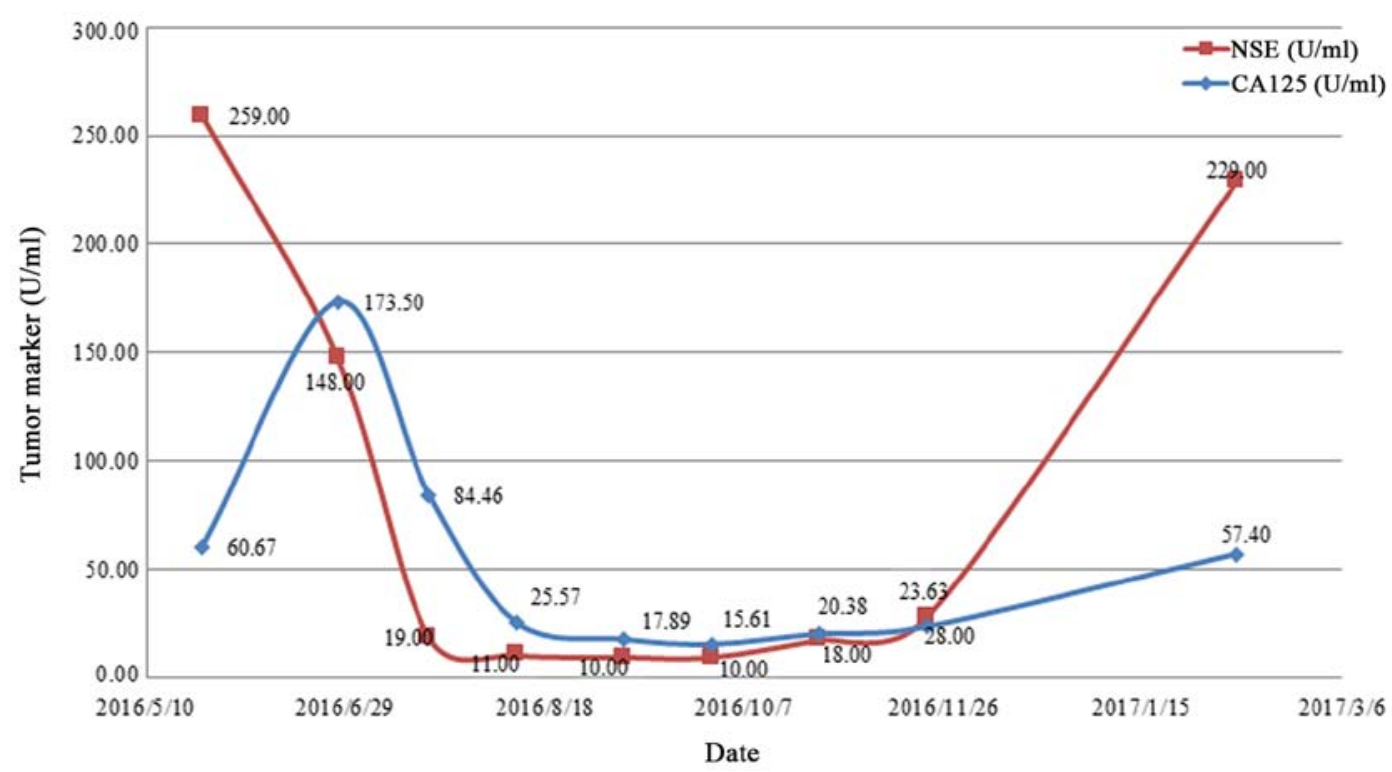

Figure 3. Changes in the tumor marker levels of the patient over time. CA125 and NSE levels decreased with disease palliation and increased with disease aggravation. CA125, carbohydrate antigen 125; NSE, neuron specific enolase.

compared with the normal range $(<8.7 \mathrm{FU} / 3 \mathrm{ml})$. A gastroscopy revealed a solitary lesion in the fundus of the stomach and a histopathological examination of a gastric specimen revealed that the patient had SCLC, which had infiltrated the mucosa and submucosa (Fig. 4 and S1).

The aforementioned gastric specimens were fixed with $10 \%$ formalin for $24 \mathrm{~h}$ and embedded in paraffin. Four to six paraffin embedded samples $(\sim 5 \mu \mathrm{m})$ including the complete tumor tissue were selected and stained as follows. Paraffin-embedded sections were deparaffinized and immersed in distilled water. The sections were rinsed three times for $5 \mathrm{~min}$ in PBS-T (0.01 M PBS pH 7.4: $\mathrm{KH}_{2} \mathrm{PO}_{4} 0.02 \%, \mathrm{~N}_{2} \mathrm{HPO}_{4} 0.29 \%, \mathrm{KCl} 0.02 \%, 0.8 \% \mathrm{NaCl}$, $0.05 \%$ BSA, $0.05 \%$ Tween-20 and $0.0015 \%$ Triton $\mathrm{X}-100$ ) prior to staining. Slides were placed in a wet chamber and sections were blocked with $3 \%$ peroxide-methanol blocking buffer for $>30 \mathrm{~min}$ at room temperature. The slides were incubated with primary antibodies against thyroid transcription factor-1 (TTF-1; cat. no. MAB-0677; 1:200; AXIM $^{\circledR}$ Biotechnologies, Inc.), synaptophysin (Syn; cat. no. kit-0022; 1:200; AXIM ${ }^{\circledR}$ Biotechnologies, Inc.), marker of proliferation Ki-67 (cat. no. ZM-0166; 1:200; OriGene Technologies, Inc.), neural cell adhesion molecule 1 (NCAM1; cat. no. kit-0028; 1:200; AXIM ${ }^{\circledR}$ Biotechnologies, Inc.), chromogranin A (CgA; cat. no. MAB-0707; 1:200; AXIM $^{\circledR}$ Biotechnologies, Inc.), cytokeratin 7 (CK7; cat. no. ZM-0069; 1:200; OriGene Technologies, Inc.), CK20 (cat. no. kit-0025; 1:200; AXIM ${ }^{\circledR}$ Biotechnologies, Inc.) and caudal type homeobox 2 (CDX-2; cat. no. RMA-0631; 1:200; AXIM $^{\circledR}$ Biotechnologies, Inc.) overnight at $4^{\circ} \mathrm{C}$. Slides were washed with PBS $(3 \times 3 \mathrm{~min})$ and incubated with horseradish peroxidase-labeled secondary antibodies (cat. no. 18G48D10, 1:200; OriGene Technologies, Inc.) for 30-60 $\mathrm{min}$ at room temperature. Slides were washed with PBS (3x3 min) and stained with 3,3'-diaminobenzidine in the dark at room temperature for $10 \mathrm{~min}$. Hematoxylin $(0.7 \%$ for $2 \mathrm{~min}$ ) was used as a counterstain for the nuclei. Images (5 fields/slice) were captured using a light microscope at x200 magnification. Immunohistochemical staining for TTF-1, NCAM1, CgA, Syn and Ki67 was positive (Fig. 3), CK7 staining was positive in a limited area, whereas CK20 and CDX-2 staining was negative (Fig. S1).

On May 30, 2016, a percutaneous biopsy of the cervical lymph node suggested the presence of SCLC, as it exhibited immunohistochemical staining features similar to those of the gastric specimen (Figs. 5 and S2). The patient was subsequently diagnosed with extensive-stage SCLC with gastric metastases and extensive lymph node metastases according to the National Comprehensive Cancer Network (NCCN) Guidelines (12).

Upon admission to the Department of Oncology, the patient had nutrition deficiency. The patient had an Eastern Cooperative Oncology Group (13) performance status of 2. Taking into consideration patient condition and age, etoposide monotherapy was started on June 7, 2016 (14). Following the first course of chemotherapy, the patient's general condition and appetite were markedly improved without significant adverse effects, such as gastrointestinal reaction. Between June 29 and November 23, 2016, the patient was treated with an additional seven courses of systemic chemotherapy with etoposide and oxaliplatin. Monthly imaging examinations revealed the effectiveness of chemotherapy (Figs. 1B-D and 2B-D), which was corroborated by a change in the expression of tumor markers. The expression of CA125 and NSE decreased with disease palliation and increased with disease aggravation (Fig. 5). However, on December 28, 2016, thoracic and abdominal CT images revealed enlarged masses, indicating disease progression (Figs. 1E and 2E). The second- and third-line chemotherapy agents, irinotecan with carboplatin (15) and gemcitabine (16), respectively, were ineffective against these masses (Figs. 1F and 2F), suggesting chemotherapy resistance developed.

The patient was referred to the Oncology Department on March 8, 2017 as the condition rapidly deteriorated, and liver dysfunction and anemia were identified. The liver function 
$H \& E$
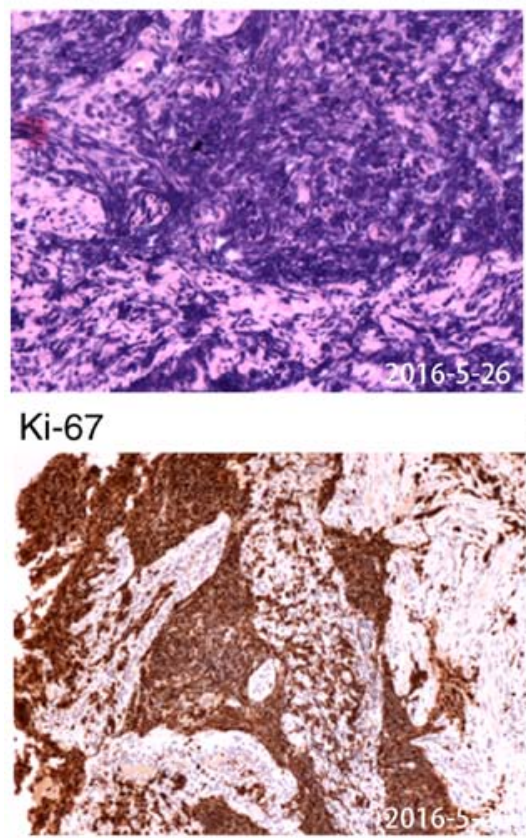

TTF-1

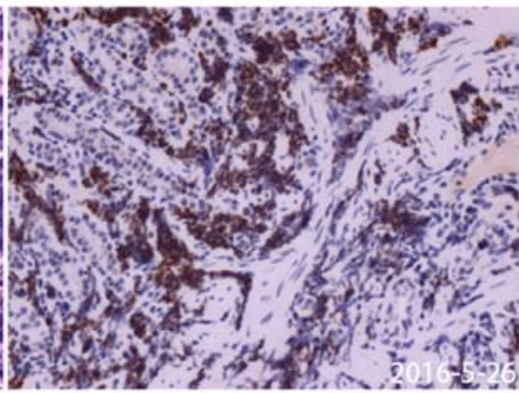

Syn

Figure 4. Histopathological view of gastroscopy biopsy specimen. The samples were collected on May 26, 2016. Typical carcinoma (H\&E) and immunohistochemistry suggesting high expression of TTF-1, Syn and Ki67 (magnification, x200). TTF-1, thyroid transcription factor-1; Syn, synaptophysin.

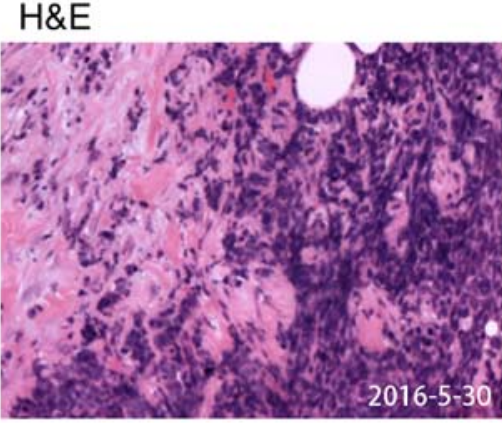

Ki-67

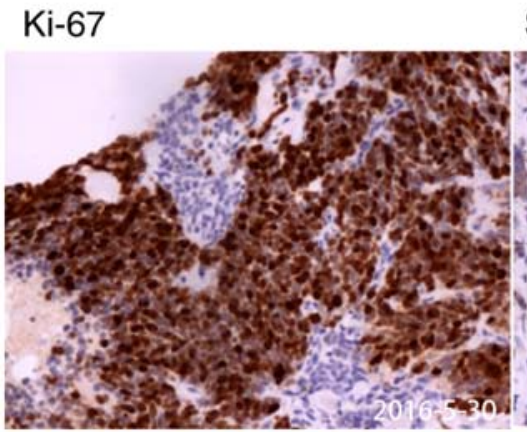

TTF-1

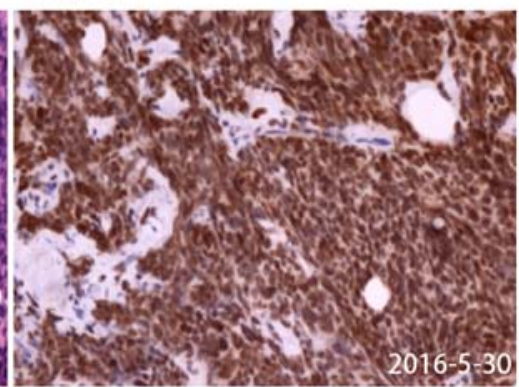

Syn

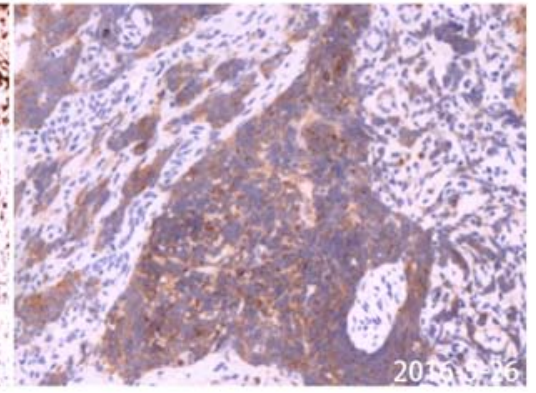

Sy

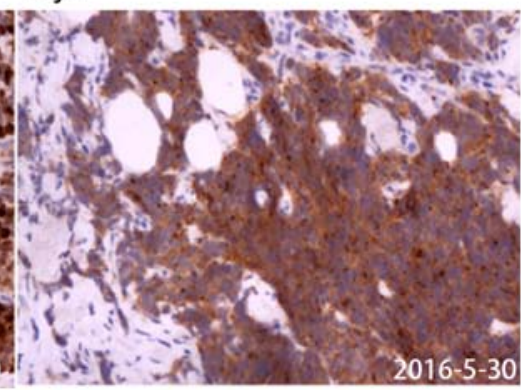

Figure 5. Histopathological view of cervical lymph node biopsy specimen. The samples were collected on May 30, 2016. Typical carcinoma (H\&E) and immunohistochemistry suggesting high expression of TTF-1, Syn and Ki67 (magnification, x200). TTF-1, thyroid transcription factor-1; Syn, synaptophysin.

test revealed $200 \mathrm{IU} / 1$ aspartate aminotransferase, $83 \mathrm{IU} / 1$ alanine aminotransferase, $69.37 \mu \mathrm{mol} / 1$ direct bilirubin and $124.75 \mu \mathrm{mol} / 1$ total bilirubin. Routine blood examination revealed $86 \mathrm{~g} / \mathrm{l}$ hemoglobin; the patient exhibited severe jaundice and anorexia. On March 9, 2017, the patient succumbed to liver failure and an autopsy was refused.

Literature review. Only a limited number of cases of SCLC gastric metastasis have previously been reported. Databases including PubMed (https://www.ncbi.nlm.nih.gov/pubmed), WanFang Data (http://www.wanfangdata.com.cn/index. html) and China National Knowledge Infrastructure (CNKI; http://kns.cnki.net/kns/brief/default_result.aspx) were investigated between October 2017 and March 2018 to analyze the clinicopathological features and outcomes of patients with SCLC and gastric metastases. Search terms included 'small cell lung cancer', 'gastric/gastrointestinal/stomach' and 'metastasis/metastases'. A total of 11 case reports (17-27) (Table I) 


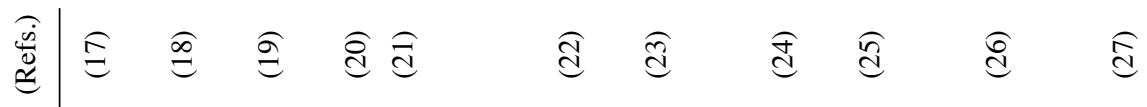

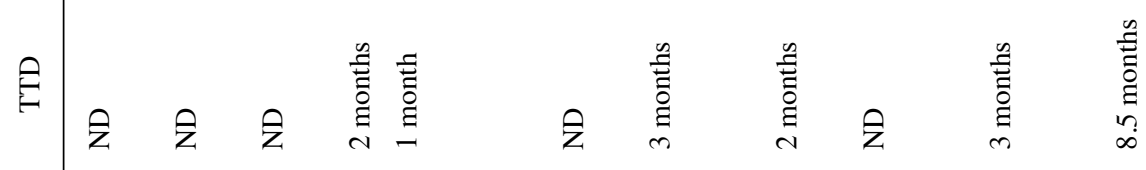

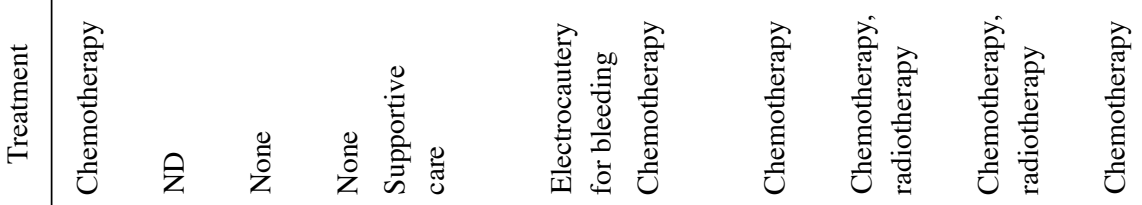

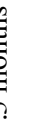

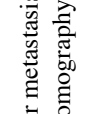

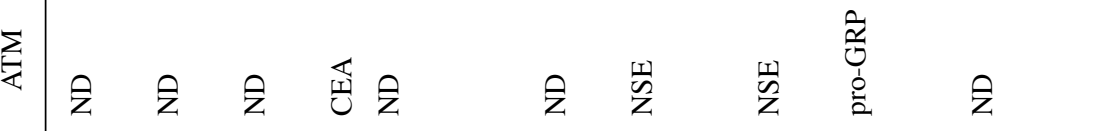

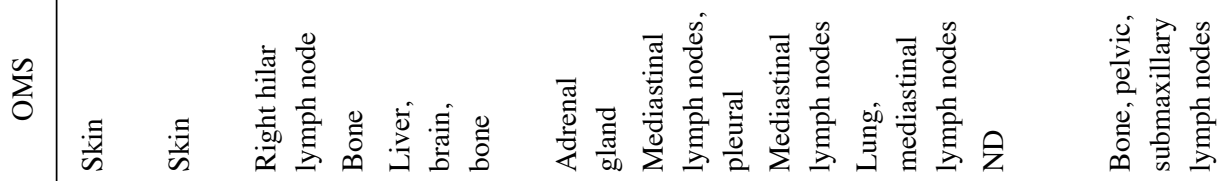

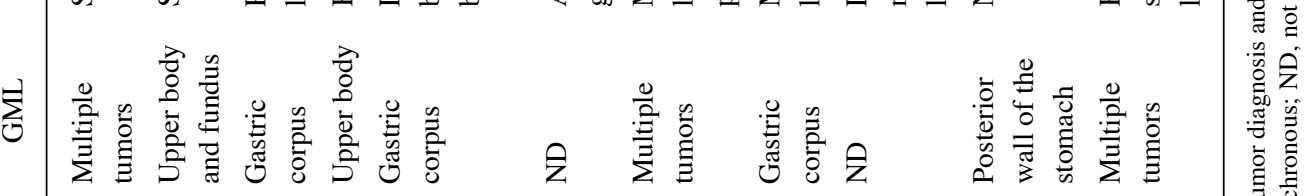

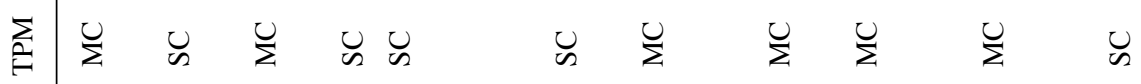

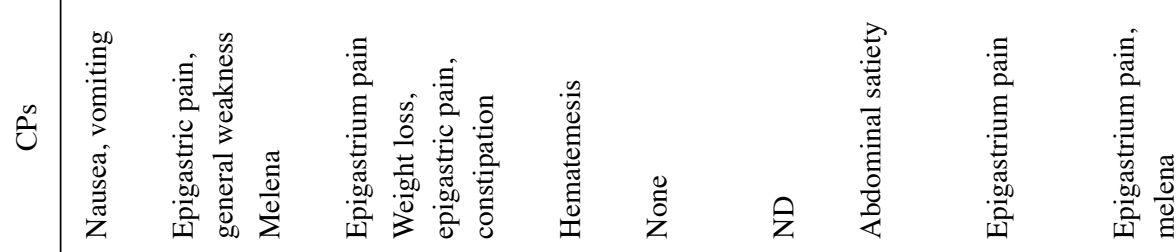

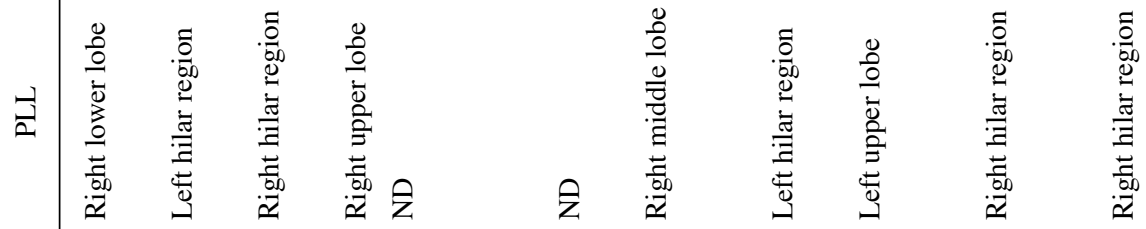

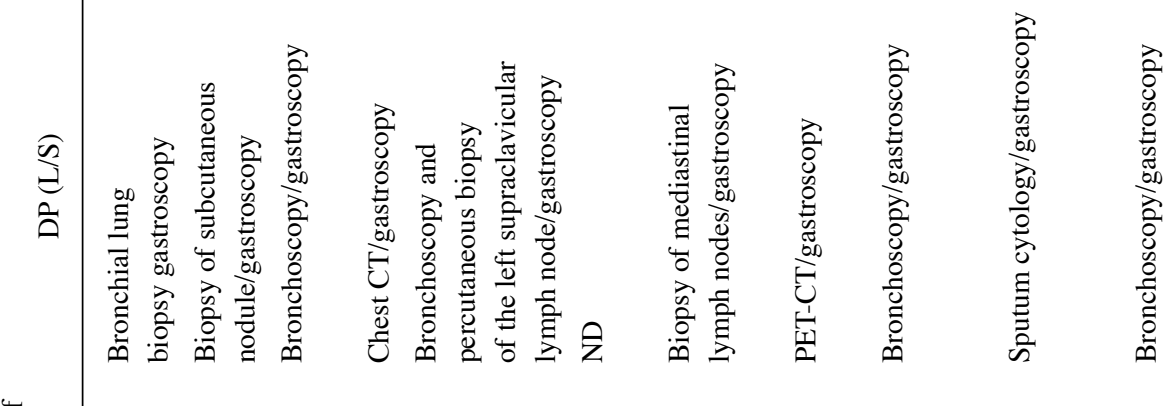

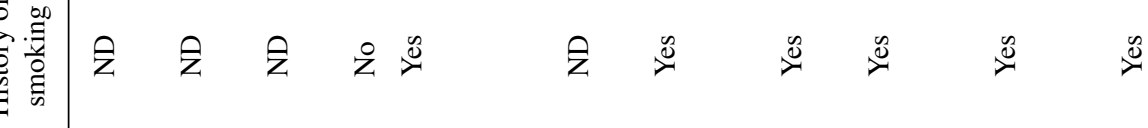

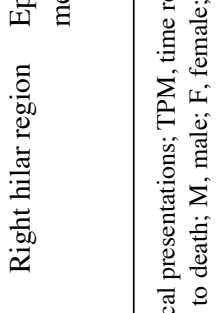


Table II. Retrospective studies describing small cell lung carcinoma with gastric metastasis.

\begin{tabular}{|c|c|c|c|c|c|c|c|}
\hline Author, year & Cases (n) & Gastric metastasis (n) & Sex & Clinical presentation & Treatment & Overall survival & (Refs.) \\
\hline Green 1990 & 67 & 11 & ND & ND & ND & ND & (28) \\
\hline Ryo et al, 1996 & 30 & 1 & ND & ND & ND & ND & (29) \\
\hline Yoshimoto et al, 2006 & 470 & 3 & ND & ND & ND & ND & (5) \\
\hline Kim et al, 2009 & 28 & 3 & ND & ND & ND & ND & (30) \\
\hline Lee et al, 2011 & 21 & 1 & M & Abdominal pain & None & 3 months & $(31)$ \\
\hline Liu et al, 2012 & 12 & 1 & M & Epigastric discomfort & Chemotherapy & 1 year & $(32)$ \\
\hline
\end{tabular}

ND, not described; M, male.

and 6 retrospective studies $(5,28-32)$ including 20 cases were reviewed (Table II). As presented in Table II, gastric metastases account for only $0.6-16.4 \%$ of the total cases of metastasis in patients with SCLC. As observed in Table I, a total of 7 of the 11 cases of SCLC with gastric metastases presented in patients $>65$ years and 9 cases were male patients. SCLC was frequently identified in patients $>65$ years with a long history of smoking. Among the 11 cases, 6 patients were smokers, 1 patient did not smoke and the information for the other 4 patients was not available. The female patient reported in the current study did not have a history of smoking or consuming alcohol and thus differed from the majority of previously reported cases.

\section{Discussion}

The treatment of SCLC is often complicated by the presence of distant metastases, which typically occur in the head, bone and adrenal gland; however, gastrointestinal metastases are less common (30). A previous analysis of 18 consecutive cases of lung cancer with gastrointestinal tract involvement reported that only 4 cases presented with stomach metastasis (33). In previous studies, the clinical prevalence of stomach metastases in patients with lung cancer was $0.035-3.4 \%$ and metastases were diagnosed by endoscopy or autopsy $(30,34)$.

Lung cancer is typically diagnosed by bronchoscopy, biopsy of the lymph nodes, positron emission tomography (PET)-CT and sputum cytology, while stomach metastases are identified via a gastroscopy (35). A systematic review and meta-analysis reported that PET/CT is a valuable tool for the diagnosis of SCLC (36). However, gastric metastasis should be distinguished from primary gastric carcinoma, as this influences the therapeutic approach. Criteria for the diagnosis of gastric metastases include morphologic and immunohistochemical features consistent with a primary pulmonary tumor, as well as the clinicoradiologic demonstration of a primary lung tumor and exclusion of tumors elsewhere (37). Xu et al (24) and Zhang et al (25) reported Ki-67 values of 95 and 60\%, respectively (Table I). The Ki-67 value of the patient described in the current study was $80 \%$. Ki-67 is of particular importance in SCLC, as it is indicative of high proliferation (38). TTF-1 is a tissue-specific transcription factor essential for the normal development of the lung and its expression has been detected in various types of lung carcinomas, including SCLC (39). Therefore, TTF-1 is used to distinguish metastatic carcinomas of pulmonary origin from other carcinomas (40). CDX2 expression is maintained in the adult small and large intestinal epithelia, and is upregulated in gastrointestinal pathological states (41). Furthermore, the co-expression of TTF-1 and neuroendocrine markers, including NCAM1, CgA and Syn, have contributed to the diagnosis of SCLC metastasis in the stomach (42).

The literature review revealed that SCLC with gastric metastasis commonly occurred in the hilar region lymph nodes, while the metastatic sites of the stomach were either scattered, single or multiple (8). It was reported that among the 54 cases diagnosed via an endoscopy, solitary lesions (65\%) presented more frequently than multiple lesions (35\%) with common metastatic sites in the middle or upper third of the stomach (3). In a clinicopathological study, the sites of metastasis in the stomach were solitary for $94.4 \%$ of patients, with 5.6\% developing multiple lesions in the stomach; and the body of the stomach was the most common site of metastasis (43).

Four different processes have been hypothesized to be involved in the metastatic spread of primary cancers to the stomach, including peritoneal and hematogenous dissemination, lymphatic spread and direct tumor invasion (2). The metastasis of lung cancer to the stomach is principally caused by hematogenous metastasis. The direct invasion of cancer cells often occurs through the pulmonary vein and the left side of the heart, resulting in transfer to organs and tissues throughout the body, including the stomach (26). SCLC has previously exhibited a high incidence of vascular invasion (6). Therefore, when gastric metastases are identified, other metastases, including skin, bone, liver, brain, adrenal gland and visceral pleura also occur (44). In addition, a previous study reported the possibility of cancer cells in phlegm being swallowed and entering the stomach, thereby causing implantation metastasis (37).

The majority of patients with gastrointestinal metastases are asymptomatic, resulting in the majority of cases being diagnosed by an autopsy. However, epigastric pain, chronic bleeding, nausea and vomiting, melena and weight loss are commonly reported and constipation, abdominal satiety and hematemesis also occur. Common complications include perforation, obstruction and ulceration due to disease progression $(45,46)$. In patients at extensive-stages of the disease, chemotherapy is the preferred therapeutic option to attenuate symptoms and prolong survival in patients; 
however, long-term survival is rare (9). The recommended first-line regimens are cisplatin and etoposide according to the NCCN Guidelines (47). However, a systematic review comparing cispatin- and carboplatin-based chemotherapy in the first-line treatment of SCLC suggested that there is no difference in efficacy between the two treatments (48). Second-line chemotherapy treatment typically includes irinotecan and gemcitabine (49). The patient in the current study received oxaliplatin to decrease the risk of severe myelosuppression and gastrointestinal reaction, and benefited from first-line chemotherapy with only mild adverse chemotherapy-associated effects. Chemotherapeutic treatment results in rapid tumor necrosis with perforation resulting in mortality and should therefore be used with caution (50). A report of 13 patients with metastatic lung cancer receiving exploratory celiotomy revealed that surgical intervention in combination with chemotherapy is effective, especially when obstruction, bleeding or perforation occur, with $8 / 13$ patients surviving and discharged from hospital after a mean stay of 17 days (51). Radiotherapy is occasionally performed in the treatment of regional tumors in the lungs, brain or lymph nodes (53).

For patients with metastasis in the upper gastrointestinal tract, prognosis is poor, with an average of 5.5 months from diagnosis to mortality (53). A previous study reported the median survival time of patients with metastasis in the upper gastrointestinal tract was 4.75 months and none survived for $>2$ years (54). The patient described in the current case report had a survival period $<1$ year.

The low prevalence and poor prognosis of patients with SCLC and gastric metastasis cannot be ignored in clinical practice. Identifying metastatic or primary gastric carcinoma may be clinically challenging; however, immunohistochemical staining aids to detect the primary origin site, which presents with an identical phenotype to the metastatic site. The pathology of tissue also contributes to the diagnosis and may impact the selection of the therapeutic regimen. SCLC is sensitive to chemotherapy; yet treatment-induced bleeding may trigger perforation and the rapid onset of mortality (50). Surgery may be possible in certain cases when obstruction, bleeding or perforation occurs; however, further studies are required in order to identify the optimal treatment for patients with SCLC and gastric metastasis.

\section{Acknowledgements}

The authors would like to thank Professor Qing Wu (English Department, School of Humanities, Beijing University of Chinese Medicine, Beijing, China) for the English language editing.

\section{Funding}

This project was funded by the National Natural Science Foundation of China (grant no. 8187151262).

\section{Availability of data and materials}

The datasets used and/or analyzed during the current study are available from the corresponding author on reasonable request.

\section{Authors' contributions}

YMP, QL and HJC collected the patient's data. YW, APS and HD analyzed the data and performed reference search. YMP, YQQ and QL drafted and revised the manuscript. All authors contributed toward data analysis, drafting and revision of the manuscript, and read and approved the final manuscript.

\section{Ethics approval and consent to participate}

This case report was approved by the China-Japan Friendship Hospital.

\section{Patient consent for publication}

Consent for publication was signed by the patient's daughter.

\section{Competing interests}

The authors declare that they have no competing interests.

\section{References}

1. Nitipir C, Ginghina O, Popa L, Andrei F, Tudor N, Radu I, Iaciu C, Orlov C, Vasilescu F, Balalau C, et al: A rare case of advanced lung cancer presenting as a symptomatic gastric tumor. Mol Clin Oncol 8: 600-602, 2018.

2. Namikawa T and Hanazaki K: Clinicopathological features and treatment outcomes of metastatic tumors in the stomach. Surg Today 44: 1392-1399, 2014

3. Oda I, Kondo H, Yamao T, Saito D, Ono H, Gotoda T, Yamaguchi H, Yoshida S and Shimoda T: Metastases tumors to the stomach: Analysis of 54 patients diagnosed at endoscope and 347 autopsy cases. Endoscopy 33: 507-510, 2001.

4. De Palma GD, Masone S, Rega M, Simeoli I, Donisi M, Addeo P, Iannone L, Pilone V and Persico G: Metastatic tumors to the stomach: Clinical and endoscopic features. World J Gastroenterol 12: 7326-7328, 2006.

5. Yoshimotoa A, Kasaharab K and Kawashima A: Gastrointestinal metastases from primary lung cancer. Eur J Cancer 42: 3157-3160, 2006.

6. Antler AS, Ough Y, Pitchumoni CS, Davidian M and Thelmo W: Gastrointestinal metastases from malignant tumors of the lung. Cancer 49: 170-172, 1982.

7. Yang CJ, Hwang JJ, Kang WY, Chong IW, Wang TH, Sheu CC, Tsai JR and Huang MS: Gastro-intestinal metastasis of primary lung carcinoma: Clinical presentations and outcome. Lung Cancer 54: 319-323, 2006.

8. Huang Q, Su X, Bella AE, Luo K, Jin J, Zhang S, Luo G, Rong $\mathrm{T}$ and $\mathrm{Fu} \mathrm{J}$ : Clinicopathological features and outcome of gastric metastases from primary lung cancer: A case report and systematic review. Oncol Lett 9: 1373-1379, 2015.

9. Demedts IK, Vermaelen KY and van Meerbeeck JP: Treatment of extensive-stage small cell lung carcinoma: Current status and future prospects. Eur Respir J 35: 202-215, 2010.

10. Cheng S, Evans WK, Stys-Norman D and Shepherd FA: Chemotherapy for relapsed small cell lung cancer: A systematic review and practice guideline. J Thorac Oncol 2: 348-354, 2007.

11. Zhou M, WangZ, Yao Y,Zhou H,Liu M and Sun J: Neuron-specific enolase and response to initial therapy are important prognostic factors in patients with small cell lung cancer. Clin Transl Oncol 19: 865-873, 2017.

12. Stahel R, Ginsberg R and Havemann K: Staging and prognostic factors in small cell lung cancer: A consensus report. Lung Cancer 5: 119-126, 1989.

13. Oken MM, Creech RH, Tormey DC, Horton J, Davis TE, McFadden ET and Carbone PP: Toxicity and response criteria of the eastern cooperation oncology group. Am J Clin Oncol 5: 649-655, 1982. 
14. Mascaux C, Paesmans M, Berghmans T, Branle F, Lafitte JJ, Lemaitre F, Meert AP, Vermylen P and Sculier JP; European Lung Cancer Working Party (ELCWP): A systematic review of the role of etoposide and cisplatin in the chemotherapy of smal cell lung cancer with methodology assessment and meta-analysis. Lung Cancer 30: 23-36, 2000.

15. Schmittel A, Fischer von Weikersthal L, Sebastian M, Martus P, Schulze K, Hortig P, Reeb M, Thiel E and Keilholz U: A randomized phase II trial of irinotecan plus carboplatin versus etoposide plus carboplatin treatment in patients with extended disease small-cell lung cancer. Ann Oncol 17: 663-667, 2006.

16. Van der Lee I, Smit EF, van Putten JW, Groen HJ, Schlösser NJ, Postmus PE and Schramel FM: Single-agent gemcitabine in patients with resistant small-cell lung cancer. Ann Oncol 12: 557-561, 2001

17. Maeda J, Miyake M, Tokita K, Iwahashi N, Nakano T, Tamura S, Hada T and Higashino K: Small cell lung cancer with extensive cutaneous and gastric metastases. Intern Med 31: 1325-1328, 1992.

18. Kim HS, Jang WI, Hong HS, Lee CI, Lee DK, Yong SJ, Shin KC and Shim YH: Metastases involvement of the stomach secondary to lung carcinoma. J Korean Med Sci 8: 24-29, 1993.

19. Chen $\mathrm{H}$, Lin YG and Liu Y: Older lung cancer patient with gastric metastasis: A case report. J Guangxi Med Univ 21: 766, 2004 (In Chinese).

20. Oh JC, Lee GS, Kim JS, Park Y, Lee SH, Kim A, Lee JM and Kim KS: A case of gastric metastasis from small cell lung carcinoma. Korean J Gastroenterol 44: 168-171, 2004.

21. Casella G, Di Bella C, Cambareri AR, Buda CA, Corti G, Magri F, Crippa S and Baldini V: Gastric metastasis by lung small cell carcinoma. World J Gastroenterol 12: 4096-4097, 2006.

22. Kim MS, Kook EH, Ahn SH, Jeon SY, Yoon JH, Han MS $\mathrm{Kim} \mathrm{CH}$ and Lee JC: Gastrointestinal metastasis of lung cancer with special emphasis on a long-term survivor after operation. J Cancer Res Clin Oncol 135: 297-301, 2009.

23. Koch B, Tannapfel A, Vieth M and Grün R: Gastric metastasis from small cell lung cancer. Pneumologie 63: 585-587, 2009 (In German).

24. Xu EW and Xui LT: Gastric metastasis from small cell lung cancer: A case report. Chin J Clin 7: 7260-7262, 2013.

25. Zhang QJ, Zhao HB and Han $\mathrm{CH}$ : Gastric metastasis by lung small cell carcinoma. J Int Oncol 42: 877-878, 2015.

26. Gao S, Hu XD, Wang SZ, Liu N, Zhao W, Yu QX, Hou WH and Yuan SH: Gastric metastasis from small cell lung cancer: A case report. World J Gastroenterol 21: 1684-1688, 2015.

27. Zhu YP, Lv WB and Wang Bo: Gastric metastasis by lung small cell carcinoma. J Mod Med Health 33: 3734-3735, 2017 (In Chinese).

28. Green LK: Hematogenous metastases to the stomach: A review of 67 cases. Cancer 65: 168-171, 1990

29. Ryo H, Sakai H, Ikeda T, Hibino S, Goto I, Yoneda S and Noguchi Y: Gastrointestinal metastasis from lung cancer. Nihon Kyobu Shikkan Gakkai Zasshi 34: 968-972, 1996 (In Japanese).

30. Kim SY, Ha HK, Park SW, Kang J, Kim KW, Lee SS, Park SH and Kim AY: Gastrointestinal metastasis from primary lung cancer: CT findings and clinicopathologic features. AJR Am J Roentgenol 193: W197-W201, 2009.

31. Lee PC, Lo C, Lin MT, Liang JT and Lin BR: Role of surgical intervention in managing gastrointestinal metastases from lung cancer. World J Gastroenterol 17: 4314-4320, 2011.

32. Liu YP, Jin B and Wang QS: Metastatic carcinoma to the stomach from different primary sites: An analysis of 12 cases. Word Chin J Digestol 20: 2092-2096, 2012 (In Chinese)

33. Rossi G, Marchioni A, Romagnani E, Bertolini F, Longo L, Cavazza A and Barbieri F: Primary lung cancer presenting with gastrointestinal tract involvement: Clinicopathologic and immunohistochemical features in a series of 18 consecutive cases. J Thorac Oncol 2: 115-120, 2007.

34. Hasegawa N, Yamasawa F, Kanazawa M, Kawashiro T, Kikuchi K, Kobayashi K, Ishihara T, Kuramochi S and Mukai M: Gastric metastasis of primary lung cancer. Nihon Kyobu Shikkan Gakkai Zasshi 31: 1390-1396, 1993 (In Japanese).
35. Rivera MP, Mehta AC and Wahidi MM: Establishing the diagnosis of lung cancer: Diagnosis and management of lung cancer, 3rd ed: American College of Chest Physicians evidence-based clinical practice guidelines. Chest 143 (Suppl 5): e142S-e165S 2013.

36. Lu YY, Chen JH, Liang JA, Chu S, Lin WY and $\mathrm{Kao} \mathrm{CH}$ : F-18-FDG PET or PET/CT for detecting extensive disease in small-cell lung cancer: A systematic review and meta-analysis. Nucl Med Commun 35: 697-703, 2014.

37. Guinee DG Jr, Fishback NF, Koss MN, Abbondanzo SL and Travis WD: The spectrum of immunohistochemical staining of small-cell lung carcinoma in specimens from transbronchial and open-lung biopsies. Am J Clin Pathol 102: 406-414, 1994.

38. Kyritsis I, Krebs B, Kampe S, Theegarten D, Aigner C and Welter S: Erroneous diagnosis of small cell lung cancer based on small biopsies with far-reaching consequences: Case report of a typical carcinoid tumor. J Thorac Dis 9: E99-E102, 2017.

39. Oliveira AM, Tazelaar HD, Myers JL, Erickson LA and Lloyd RV: Thyroid transcription factor-1 distinguishes metastatic pulmonary from well-differentiated neuroendocrine tumors of other sites. Am J Surg Pathol 25: 815-819, 2001.

40. Stenhouse G, Fyfe N, King G, Chapman A and Kerr KM: Thyroid transcription factor 1 in pulmonary adenocarcinoma. J Clin Pathol 57: 383-387, 2004.

41. Saqi A, Alexis D, Remotti F and Bhagat G: Usefulness of CDX2 and TTF-1 in differentiating gastrointestinal from pulmonary carcinoids. Am J Clin Pathol 123: 394-404, 2005.

42. Miskovic J, Brekalo Z, Vukojevic K, Miskovic HR, Kraljevic D, Todorovic J and Soljic V: Co-expression of TTF-1 and neuroendocrine markers in the human fetal lung and pulmonary neuroendocrine tumors. Acta Histochem 117: 451-459, 2015

43. Wu MH, Lin MT and Lee PH: Clinicopathological study of gastric metastases. World J Surg 31: 132-136, 2007.

44. Van Meerbeeck JP, Fennell DA and De Ruysscher DK: Small-cell lung cancer. Lancet 378: 1741-1755, 2011.

45. Alibazoglu H, Alibazoglu B, Ali A and La Monica G: False-negative FDG PET imaging in a patient with metastasis melanoma and ideal intussusception. Clin Nucl Med 24: 129, 1999.

46. Capasso L, Iarrobino G, D' Ambrosio R, Carfora E, Ventriglia R and Borsi E: Surgical complications for gastric and small bowel metastasis due to primary lung carcinoma. Minerva Chir 59: 397-403, 2004

47. Evans WK, Shepherd FA, Feld R, Osoba D, Dang P and Deboer G: VP-16 and cisplatin as frst-line therapy for small-cell lung cancer. J Clin Oncol 3: 1471-1477, 1985.

48. Rossi A, Di Maio M, Chiodini P, Rudd RM, Okamoto H, Skarlos DV, Früh M, Qian W, Tamura T, Samantas E, et al: Carboplatin- or cisplatin-based chemotherapy in first-line treatment of small-cell lung cancer: The COCIS meta-analysis of individual patient data. J Clin Oncol 30: 1692-1698, 2012.

49. Owonikoko TK, Behera M, Chen Z, Bhimani C, Curran WJ, Khuri FR and Ramalingam SS: A systematic analysis of efficacy of second-line chemotherapy in sensitive and refractory small-cell lung cancer. J Thorac Oncol 7: 866-872, 2012.

50. Medell A and Lochman D: An unusual metastatic manifestation of a primary bronchogenic carcinoma. Cancer 30: 806-809, 1972.

51. Woods JM IV and Koretz MJ: Emergency abdominal surgery for complications of metastatic lung carcinoma. Arch Surg 125: 583-585, 1990.

52. Slotman BJ and Senan S: Radiotherapy in small-cell lung cancer: Lessons learned and future directions. Int J Radiat Oncol Biol Phys 79: 998-1003, 2011.

53. Brady LW, O'Neill EA and Farber SH: Unusual sites of metastases. Semin Oncol 4: 59-64, 1977.

54. Campoli PM,Ejima FH, Cardoso DM, Silva OQ, Santana Filho JB, Queiroz Barreto PA, Machado MM, Mota ED, Araujo Filho JA, Alencar Rde C and Mota OM: Metastatic cancer to the stomach. Gastric Cancer 9: 19-25, 2006. 